\title{
Clinical Reasoning: A 55-year-old obese woman with headache and rhinorrhea
}

Jenna Conway, MD, Scott Grossman, MD, Shelley Varnado, MD, Steven Frucht, MD, Laura Balcer, Mia Minen, and Steven Galetta, MD

Neurology ${ }^{\circledR}$ 2019;92:e2614-e2617. doi:10.1212/WNL.0000000000007582
Correspondence

Dr. Conway

jenna.conway@nyumc.org

\section{Section 1}

A 55-year-old obese woman with a history of migraine and tension-type headaches presented with headache for 5 days with acute worsening for 1 day. The headache was throbbing, holocephalic, and maximal at the left temple, and worsened with both standing and lying down and with exertion. The headache was initially mild for 4 days before acutely worsening in severity and waking her from sleep with associated nausea and photophobia. Unlike her typical headaches, it did not improve with over-the-counter analgesics and was more prolonged. There were no associated visual complaints, hearing changes or phonophobia, jaw claudication, weakness, numbness, or paresthesias.

On initial examination, the patient was a middle-aged African American woman who was obese with a body mass index (BMI) of 46 . She was afebrile without nuchal rigidity and with preserved mental status. Corrected visual acuity was 20/20-2 OD and 20/25 OS at distance. Visual fields were full to confrontation, pupillary responses were intact without an afferent defect, the optic discs appeared normal on funduscopy, and ocular motility was normal. Sensation was intact and symmetric to all modalities. Strength was full and symmetric. Coordination was intact and her gait was narrow-based.

\section{Questions for consideration:}

1. What is the differential diagnosis?

2. What should be the next steps in evaluation?

GO TO SECTION 2 


\section{Section 2}

The differential diagnosis included primary CNS disorders, inflammatory processes, space-occupying lesions, vascular etiologies, and infectious processes. Initial mild headache in a known patient with migraine lasting 4 days raises suspicion for status migrainosus. Given maximal unilateral temporal pain, temporal arteritis should also be considered. Pain worse on exertion may be seen with migraine, but may also reflect increased intracranial pressure (ICP) or a meningeal process. Classically, worsening pain with lying down implies intracranial hypertension, while worsening with standing suggests intracranial hypotension; however, positional changes can be nonspecific or absent. ${ }^{1}$ Furthermore, acute worsening may be secondary to an acute infectious or vascular process.

Initial laboratory studies were notable for white blood cells (WBCs) of 10.5 with neutrophilic predominance (75\%) and elevated erythrocyte sedimentation rate (ESR) of 52. Remaining serum laboratory studies were normal. Noncontrast head CT demonstrated partially effaced sulci, empty sella, and tonsillar ectopia concerning for intracranial hypertension. The patient underwent lumbar puncture in the emergency department in seated position given body habitus, thus opening pressure was not recorded. Her CSF studies were notable for WBC of 6 (reference $0-5$ ) with neutrophilic predominance (98\% neutrophils). Remaining CSF studies were unremarkable, including negative meningitisencephalitis panel. She received IV fluids, analgesics, and antiemetics, without headache relief.

MRI brain with and without contrast (figure, $\mathrm{A}$ and $\mathrm{B}$ ) demonstrated narrow ventricles and sulcal effacement, an empty sella, and trace fluid in the left sphenoid sinus, read as likely related to sphenoidal mucosal disease given absence of CSF rhinorrhea. Magnetic resonance venography brain (figure, C) showed bilateral transverse sinus narrowing and was negative for thrombosis.

While undergoing workup, the patient developed emesis, jaw pain, and left temporal tenderness to palpation. She reported clear fluid leaking from her left nare while leaning forward and postnasal drip with a salty character. Repeat laboratory studies demonstrated worsening peripheral leukocytosis (WBC 12.8, $85 \%$ neutrophils), ESR above 130, and C-reactive protein (CRP) of 227.

\section{Questions for consideration:}

1. How do the new findings modify the differential and what further workup is required?

2. What are the most important next steps in management?

Figure Axial fluid-attenuated inversion recovery (FLAIR) MRI, sagittal postcontrast T1-weighted MRI, and magnetic resonance venography (MRV) brain

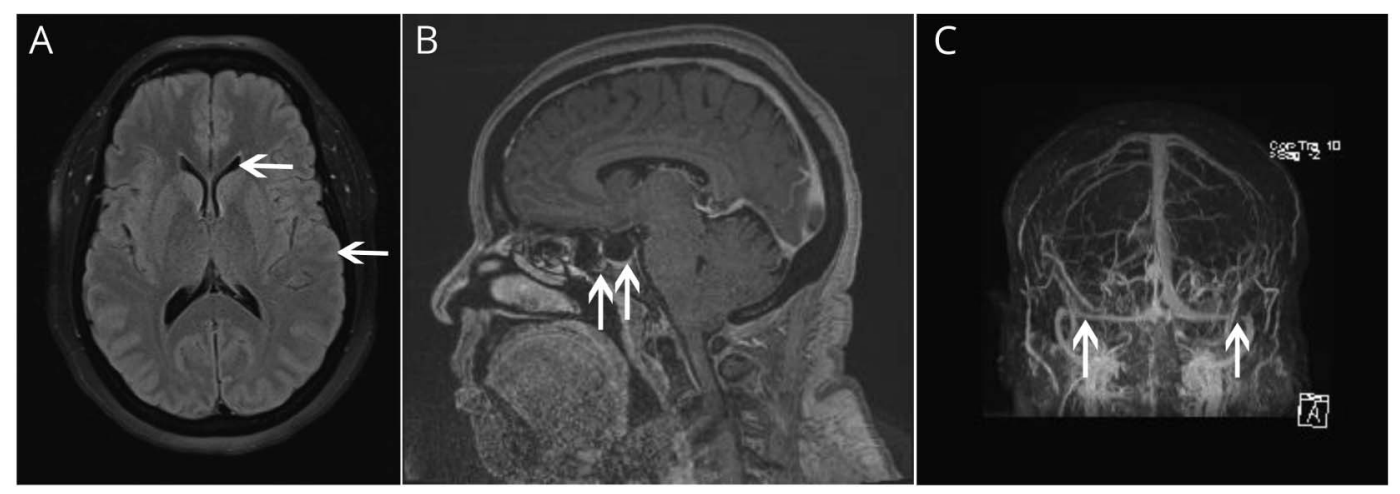

(A) Axial FLAIR MRI demonstrates narrow ventricles (top arrow) and sulcal effacement (bottom arrow). (B) Sagittal postcontrast T1-weighted MRI demonstrates trace fluid in the left sphenoid sinus (left arrow) and an empty sella (right arrow). (C) MRV brain demonstrates bilateral transverse sinus stenosis (left and right arrows) without venous sinus thrombosis.

GO TO SECTION 3 


\section{Section 3}

The new jaw pain, temporal tenderness, and elevated inflammatory markers were concerning for temporal arteritis; however, this was deemed unlikely given her relatively young age, ethnicity, and jaw pain not worsening by chewing, thus not consistent with jaw claudication. The presentation was more concerning for infection, particularly given the markedly elevated ESR/CRP. In addition, clear fluid from the patient's left nare was concerning for CSF leak.

A reservoir test was positive for clear fluid rhinorrhea. Cisternogram confirmed CSF leak with focal dehiscence in the left sphenoid sinus posterior wall. Repeat CSF studies revealed an elevated opening pressure of $38 \mathrm{cmH}_{2} \mathrm{O}(30 \mathrm{~mL}$ removed, closing pressure not recorded) and worsened pleocytosis (WBC 72 vs red blood cells 165 without xanthrochromia) with a new lymphocytic predominance $(21 \%$ neutrophils, 70\% lymphocytes). Remaining CSF studies were normal including infectious studies. The patient reported mildly improved headache immediately after. Broad-spectrum antibiotics and acetazolamide were initiated and the patient subsequently underwent surgical leak repair and ventricular shunt placement with marked improvement in headache. Acetazolamide was used for 10 days until ventricular drain was converted to ventriculoatrial shunt and the patient completed a 2 -week course of antibiotics. With her ventriculoatrial shunt in place, she underwent computerized visual fields and retinal nerve fiber layer measurements by optical coherence tomography, which were all normal. At 3-month follow-up, she reported intermittent pulsatile tinnitus and headache, worse lying down, and occasionally requiring opioids. She is awaiting follow-up for shunt reprograming and will consider restarting acetazolamide in the interim.

The unifying diagnosis is that of likely chronic intracranial hypertension from idiopathic intracranial hypertension (IIH) causing bony erosion and thus CSF leak complicated by meningitis. The patient's intracranial hypertension is likely chronic as supported by her imaging findings. Bony erosion typically suggests a chronic process (e.g., IIH) rather than an acute process (e.g., meningitis). In addition, the bilateral transverse sinus stenosis is a common (up to 90\%) though nonspecific finding in $\mathrm{IIH}^{2}$. The patient's initial mild headache that worsened with standing and lying down likely corresponded to CSF leak onset in a patient with preexisting high ICP. The acute worsening suggests onset of meningitis, which may be a complication of CSF leak from direct entry of pathogens into the CNS; however, a mild pleocytosis can also occur from the leak itself. It is worth noting that meningitis can also cause elevated ICP and thus the patient cannot be definitively diagnosed with $\mathrm{IIH}$ at time of presentation.

\section{Discussion}

IIH is defined by signs and symptoms of increased ICP (e.g., headache, vision loss, papilledema, or pulsatile tinnitus), elevated ICP above $25 \mathrm{~cm} \mathrm{H}_{2} \mathrm{O}$ with normal CSF composition, and without another cause of elevated ICP. ${ }^{3}$ While papilledema is often present in $\mathrm{IIH}$, it can be absent, in which case headache with obesity and pulsatile tinnitus suggests $\mathrm{IIH}$, thus ensuring presence of other factors when papilledema is absent can help avoid overdiagnosis in $\mathrm{IIH}^{4}{ }^{4} \mathrm{IIH}$ is most common in obese women of childbearing years.

The exact mechanism of IIH is not fully understood. Proposed etiologies include cerebral venous outflow abnormalities (e.g., venous stenoses and venous hypertension), increased CSF outflow resistance (at the level of the arachnoid granulations or CSF lymphatic drainage sites), decreased interstitial CSF flow (via congestion of the more recently discovered glymphatic, a.k.a. glial/lymphatic system), obesityrelated increased abdominal and intracranial venous pressure, altered sodium and water retention mechanisms, and abnormalities of vitamin A metabolism. ${ }^{2,5}$

$\mathrm{IIH}$ is increasingly recognized as a cause of spontaneous CSF leak from skull base erosion secondary to increased ICP. Patients may be asymptomatic or have minimal leak-related symptoms (e.g., rhinorrhea, low-pressure headache, or bacterial meningitis). The diagnosis of IIH typically occurs following surgical leak repair with onset of elevated ICP and associated symptoms. ${ }^{6}$ Furthermore, the lack of papilledema in $\mathrm{IIH}$ patients with CSF leak has been explained by the leak acting as a route of spontaneous CSF diversion to prevent papilledema. ${ }^{6}$ There is evidence to suggest that CSF leak repair in IIH, without treating the underlying raised ICP, can result in papilledema. ${ }^{6}$

Therapeutic approaches to $\mathrm{IIH}$ are targeted at treating headache and preventing progressive vision loss. It is essential to establish the degree of vision loss at diagnosis to guide treatment. No established guidelines to standardize treatment of IIH exist.

One of the mainstays of treatment in IIH is weight loss. A recent prospective randomized controlled trial (RCT) studying weight loss of $5 \%-10 \%$ in IIH (BMI > 25) on lowenergy diet demonstrated significant improvement in ICP, headache, papilledema, and visual/auditory symptoms. ${ }^{7}$ Weight loss from bariatric surgery (for BMI $>40$ ) is also associated with improved ICP and symptoms in IIH.

Medical therapy remains an important means of controlling $\mathrm{IIH}$, especially for mild vision loss. Acetazolamide, a potent carbonic anhydrase inhibitor that reduces CSF production, is a first-line agent (as in our patient). The IIH Treatment Trial (IIHTT, 2014) was an important multisite RCT designed to establish the efficacy of acetazolamide vs placebo in IIH. The IIHTT provided Class 1 evidence that acetazolamide (mean dose $2.5 \mathrm{~g}$ daily) combined with a low-sodium diet, compared with diet alone, improved visual field function and that acetazolamide is both safe and well-tolerated up to $4 \mathrm{~g}$ daily. ${ }^{8}$ However, acetazolamide did not improve headache, highlighting the importance of also treating headache in IIH. 
Topiramate, a weak carbonic anhydrase inhibitor, can also be used in IIH and is increasingly favored for its migraine prophylaxis and weight loss effects. Furosemide is occasionally used for IIH, but few data support its use.

Besides bariatric surgery, other surgical interventions for IIH include optic nerve sheath fenestration (ONSF), CSF shunting (as in our patient), and venous sinus stenting, which are typically pursued for progressive or rapid vision loss, though no large RCTs exist for validation. ONSF improves papilledema, visual acuity, and visual field defects in IIH. ${ }^{9}$ CSF diverting procedures are used for progressive vision loss refractory to medical management and improve acuity. ${ }^{10}$ Dural venous sinus stenting for IIH improves ICP, headache, papilledema, and pulsatile tinnitus. ${ }^{10}$

\section{Acknowledgment}

The authors thank the patient and her family.

\section{Study funding}

No targeted funding reported

\section{Disclosure}

The authors report no disclosures relevant to the manuscript. Go to Neurology.org/N for full disclosures.

\section{Appendix Authors}

\begin{tabular}{llll}
\hline Name & Location & Role & Contributions \\
\hline $\begin{array}{l}\text { Jenna } \\
\text { Conway, } \\
\text { MD }\end{array}$ & New & Author & $\begin{array}{l}\text { Designed and conceptualized } \\
\text { study, acquisition of data, analyzed } \\
\text { the data, drafted the manuscript for } \\
\text { intellectual content }\end{array}$ \\
\hline $\begin{array}{l}\text { Scott } \\
\text { Grossman, } \\
\text { MD }\end{array}$ & Yow, NY & Author & $\begin{array}{l}\text { Designed and conceptualized } \\
\text { study, acquisition of data, analyzed } \\
\text { the data, drafted the manuscript for } \\
\text { intellectual content }\end{array}$ \\
\hline
\end{tabular}

Appendix (continued)

\begin{tabular}{|c|c|c|c|}
\hline Name & Location & Role & Contributions \\
\hline $\begin{array}{l}\text { Shelley } \\
\text { Varnado, } \\
\text { MD }\end{array}$ & $\begin{array}{l}\text { New } \\
\text { York, NY }\end{array}$ & Author & $\begin{array}{l}\text { Designed and conceptualized } \\
\text { study, acquisition of data, analyzed } \\
\text { the data, drafted the manuscript for } \\
\text { intellectual content }\end{array}$ \\
\hline $\begin{array}{l}\text { Steven } \\
\text { Frucht, MD }\end{array}$ & $\begin{array}{l}\text { New } \\
\text { York, NY }\end{array}$ & Author & Interpreted the data \\
\hline $\begin{array}{l}\text { Laura } \\
\text { Balcer, MD }\end{array}$ & $\begin{array}{l}\text { New } \\
\text { York, NY }\end{array}$ & Author & Interpreted the data \\
\hline $\begin{array}{l}\text { Mia Minen, } \\
\text { MD }\end{array}$ & $\begin{array}{l}\text { New } \\
\text { York, NY }\end{array}$ & Author & $\begin{array}{l}\text { Interpreted the data, revised the } \\
\text { manuscript for intellectual content }\end{array}$ \\
\hline $\begin{array}{l}\text { Steven } \\
\text { Galetta, } \\
\text { MD }\end{array}$ & $\begin{array}{l}\text { New } \\
\text { York, NY }\end{array}$ & Author & $\begin{array}{l}\text { Interpreted the data, revised the } \\
\text { manuscript for intellectual content }\end{array}$ \\
\hline
\end{tabular}

\section{References}

1. Mokri B. Spontaneous CSF leaks: low CSF volume syndromes. Neurol Clin 2014;32: $397-422$.

2. Biousse V, Bruce BB, Newman NJ. Update on the pathophysiology and management of idiopathic intracranial hypertension. J Neurol Neurosurg Psychiatry 2012;83: 488-494.

3. Friedman DI, Liu GT, Digre KB. Revised diagnostic criteria for the pseudotumor cerebri syndrome in adults and children. Neurology 2013;81:1159-1165.

4. Wang SJ, Silberstein SD, Patterson S, Young WB. Idiopathic intracranial hypertension without papilledema: a case-control study in a headache center. Neurology 1998;51: 245-249.

5. Lenck S, Radovanovic I, Nicholson P, Hodaie M, Krings T, Mendes-Pereira V. Idiopathic intracranial hypertension: the veno glymphatic connections. Neurology 2018; 91:515-522.

6. Perez MA, Bialer OY, Bruce BB, Newman NJ, Biousse V. Primary spontaneous cerebrospinal fluid leaks and idiopathic intracranial hypertension. J Neuroophthalmol 2013;33:330-337.

7. Sinclair AJ, Burdon MA, Nightingale PG, et al. Low energy diet and intracranial pressure in women with idiopathic intracranial hypertension: prospective cohort study. BMJ 2010;341:c2701.

8. Wall M, McDermott MP, Kieburtz KD, et al. Effect of acetazolamide on visual function in patients with idiopathic intracranial hypertension and mild visual loss: the idiopathic intracranial hypertension treatment trial. JAMA 2014;311:1641-1651.

9. Ko MW. Idiopathic intracranial hypertension. Curr Treat Options Neurol 2011;13: $101-108$.

10. Satti SR, Leishangthem L, Chaudry MI. Meta-analysis of CSF diversion procedures and dural venous sinus stenting in the setting of medically refractory idiopathic intracranial hypertension. AJNR Am J neuroradiology 2015;36: 1899-1904. 


\section{Neurology}

\section{Clinical Reasoning: A 55-year-old obese woman with headache and rhinorrhea}

Jenna Conway, Scott Grossman, Shelley Varnado, et al.

Neurology 2019;92; $2614-\mathrm{e} 2617$

DOI 10.1212/WNL.0000000000007582

This information is current as of May 27, 2019

Updated Information \&
Services

References

Subspecialty Collections

Permissions \& Licensing

Reprints including high resolution figures, can be found at: http://n.neurology.org/content/92/22/e2614.full

This article cites 10 articles, 6 of which you can access for free at: http://n.neurology.org/content/92/22/e2614.full\#ref-list-1

This article, along with others on similar topics, appears in the following collection(s):

Idiopathic intracranial hypertension

http://n.neurology.org/cgi/collection/idiopathic_intracranial_hypertensi on

Low pressure syndrome

http://n.neurology.org/cgi/collection/low_pressure_syndrome Meningitis

http://n.neurology.org/cgi/collection/meningitis

Visual fields

http://n.neurology.org/cgi/collection/visual_fields

Information about reproducing this article in parts (figures,tables) or in its entirety can be found online at:

http://www.neurology.org/about/about_the_journal\#permissions

Information about ordering reprints can be found online:

http://n.neurology.org/subscribers/advertise

Neurology ${ }^{\circledR}$ is the official journal of the American Academy of Neurology. Published continuously since 1951, it is now a weekly with 48 issues per year. Copyright @ 2019 American Academy of Neurology. All rights reserved. Print ISSN: 0028-3878. Online ISSN: 1526-632X.

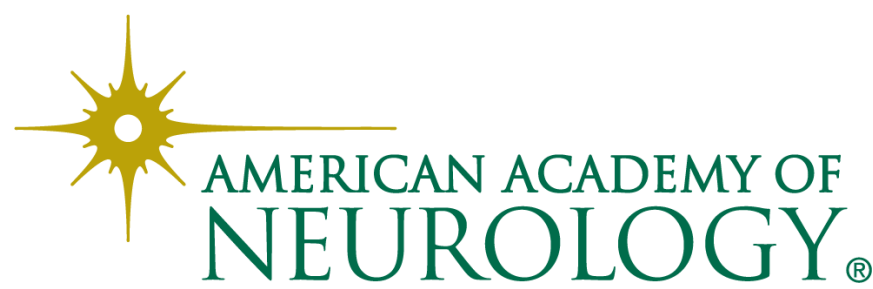

